\title{
Research on Dynamic Mechanism and Operation of Cultural Development
}

\author{
Yiwu HUANG \\ Chongqing Academy of Social Science, Chongqing, China \\ Lu LI \\ Chongqing Industry Polytechnic College, Chongqing, China
}

\begin{abstract}
Culture is a nation's lifeblood and people's spiritual home. The development of culture needs to scientifically establish a dynamic mechanism. The dynamic mechanism of cultural development mainly contains the goal orientation, heritage and development, innovation-driven, as well as ensuring system etc. And its establishment needs to grasp the rules of operation. Its operation mainly contains dynamic exploration, cultivation, transformation, feedback, and establishing, perfecting the dynamic mechanism and operation of cultural development, constantly promoting its development and prosperity.
\end{abstract}

KEYWORD: Cultural Development, Cultural Dynamics, Dynamic Mechanism, Dynamic Operation

\section{INTRODUCTION}

Cultural development is an important part of social development, whose universal law of its development also follows that of society. Unlike economic development, Culture is spiritual. It is easy to define material standards; while it is still not easy to define cultural development and progress. Fundamentally speaking, it is the growing spiritual and cultural needs of people to be satisfied, the development of the spiritual and cultural needs of the carrier or the corresponding ways to ascend. This carrier or attachment on the carrier in the related system is a kind of dynamic. And society development needs dynamics which mainly contain cultural productivity, cultural consumption, cultural creativity, cultural attractions, cultural communication, cultural sustainability etc.; to be specific, social contradiction is the basic dynamic of cultural development, while revolution and reform being the direct driving force, science and technology being the great lever etc. These dynamics inject new vigor and vitality into the development of culture, and promote the overall progress of civilization.

\section{CULTURAL DEVELOPMENT NEEDS TO ESTABLISH SCIENTIFIC DYNAMIC MECHANISM}

It is needed to establish scientific dynamic system to promote the development of culture. With the development and progress of civilization, the progress and evolution of culture with different characteristics of times, promote culture upgrading gradually. From a periodic point of view, the fusions and the struggles among different cultures which are also the dynamics of cultural development develop and debilitate cultures, which is a cultural progress. The cultural development needs certain dynamics, under which the members of society play their own roles continuously to create the increasing spiritual and cultural wealth so that the entire society can develop and make progress constantly. From a meaningful point of view, it mainly contains three aspects. Firstly, the dynamic mechanism of cultural development can utmost stimulates people's enthusiasm and creativity. The masses of the people are the power to promote the development of history, so it is necessary to grasp the people's demand for spiritual culture, to mobilize the masses to participate in all aspects of culture construction, and to promote cultural development and prosperity. Secondly, the dynamic mechanism of cultural development is to promote the dynamics for the cultural system forward being stimulated to work and coordinate. The stability of innovative dynamic mechanism and its function can make the whole running culture system move from being spontaneous to conscientious, from passive to active. Thirdly, the dynamic mechanism of cultural development is the key to promote the scientific development of culture. Cultural development depends on not only the factor levels of the dynamic system, including the level of productivity, the reform of the thrust, science and technology 
innovation, cultural spirit motivation etc. but also its structure and internal relationship. To promote the scientific development of culture, it is necessary to establish and perfect a scientific dynamic mechanism.

\section{CULTURAL DEVELOPMENT DYNAMIC MECHANISM IS THE CONTENT OF THE WHOLE SYSTEM}

The dynamics of cultural development is a mode of action of internal and external forces to promote series of motion, change and development of culture; is to make all cultural factors, parts, and links to form the structures and functions of the benign operation in the interaction; is to maximize the role of culture in a series of innovative means, tools, forms and approaches. To give full play to the role of these dynamic factors, it is needed to construct it to be a vibrant, highly efficient, much open, institution and mechanism which is conducive to scientific development of culture, to effectively implement the dynamics of cultural development, to innovate the contents and forms of culture, to liberate and develop cultural productivity. Dynamic mechanism of the cultural development contains four aspects.

\subsection{Object oriented mechanism}

The cultural development of the fundamental aim is to serve people and to educate, cultivate as well as affect people by culture so as to improve people's ideological consciousness, moral cultivation, spirit and comprehensive quality and promote the allround development of people. The cultural development dynamics must be around its aim to mobilize many elements of the cultural development dynamics. Development itself is not the final goal, but people-oriented and people's spiritual and cultural needs to be satisfied as the orientation. From this perspective, the orientation itself is a kind of dynamic, i.e. centripetal force. Under the socialist system, the essential goal for cultural development is to meet people's basic cultural demands, guarantee people's basic cultural rights and interests. During this process of realizing the goal, it is needed to strengthen the construction of socialist core value system, to play its leading and dominant role by using it to affect people, to condense force, strengthen and consolidate the base for cultural construction.

\subsection{Inheritance of the development mechanism}

Cultural heritage is not only the inheritance, propagation of culture, but also the creation and development of culture. From the endogenous dynamic of culture, cultural heritage is an important means to maintain the vitality of culture. Cultural inheritance refers that people must inherit and carry on their own traditional culture. Therefore, from the dynamic point of view, it is not only to inherit the essence of traditional culture, but also the vitality and vigor of the traditional culture, as well as the creation of internal vitality and external motivation. Hence it is necessary to well maintain the relationship between new and old culture, traditional and foreign culture. At the same time, the innovation and development are necessary for finding out the influential factors and the inherent law of the cultural development, and for analysis of operation mechanism of the dynamics to rebuild up the inheritance and development of the dynamics of cultural development so as to better serving the development of culture. In terms of the construction of socialist cultural development and prosperity, we must inherit and carry forward the traditional culture, excavate and summarize the basic spirit of distinguished traditional Chinese culture, absorb some other positive culture from all civilizations to transform and develop into that of the advanced socialism.

\subsection{Innovation driving mechanism}

Innovation is the soul of cultural development. The culture innovation has three levels of connotation: updating the cultural patterns and mode of development, creating of new cultural results, changing the existing cultural patterns and forms. Cultural innovation is to break through the existing cultural limitations, to explore new culture mode, and to transform from the old to a new cultural form. Cultural innovation mainly includes the innovation mechanism of cultural spirit, cultural knowledge, cultural environment, cultural education and culture industry. The realization of the cultural innovation is the subject of culture, the ability to highlight the realistic cultural creation process. The main element of the dynamics of cultural development is the people. With its base of serving for the development, the innovation is to stimulate people's objective understanding of the cultural development dynamics, to create more distinguished, advanced cultural achievements in order to promote the development of society and human and the progress of civilization. In the background of constructing socialist cultural power, a correlative system should be established to implement the policy of "all flowers bloom together","contention of a hundred schools of thought",(flourishing), in the direction of serving the people and socialism, to make cultural innovation as normalcy which is widely recognized by social members by establishing scientific driving mechanism of cultural innovation. 


\subsection{System security mechanism}

The dynamics of culture development involves many factors, the effective implementation which can be guaranteed by application of the system, such as the construction of culture in need of market, funds, intelligence, environment, personnel, organization and so on. In order to integrate these elements, it is needed to reform of the cultural management system, to ensure achieving the goal of cultural development by the corresponding laws, property rights, and policies etc. To establish a vibrant, rich and colorful cultural market, it is necessary to introduce the management system of modern enterprise, incentive system, distribution system, decision-making system, competition system into the field of culture or cultural enterprise, through the market operation of more prosperous cultural market. This can not only create a richer, more exciting cultural product, but also provide a powerful material guarantee for the reproduction of cultural products. Establishing perfect laws and regulations which are in accord with the culture, social development, consistent with the orientation of socialist development, and can reflect the fundamental interests of the broad masses of the people should be allowed. To establish appropriate regulation to promote development of the cultural management model, in the process of cultural management, sufficient freedom should be given. The ultimate goal of management is to serve for the legal culture creativity; the real service is not limit but providing cultural creation platform, giving culture-creation people money, materials and multilevel supports. It can not only produce more cultural products to meet the growing cultural needs of the masses, but also provide the necessary materials for the creator of the cultural products.

\section{THE CULTURAL DEVELOPMENT NEEDS THE EFFECTIVE OPERATION OF THE CULTURAL DYNAMIC MECHANISM}

Mechanism refers to the process and mode of interaction among organizations or parts in a working system. Dynamic mechanism of cultural development is the focus to optimize cultural development dynamics; scientific and systematic construction of cultural development operation mechanism contribute to study the law of cultural development, to solve many problems in the process of it, and is conducive to optimizing the allocation and combination of cultural elements so as to improve the efficiency of the cultural construction and provide the driving force for the cultural development. To establish an orderly, healthy cultural development dynamic operation mechanism includes five aspects.

\subsection{Dynamic excavation}

Dynamic excavation also refers to the innovation and integration of many factors involved in the cultural development. Dynamic excavation is the basis of dynamic operation. On the one hand, it needs us to stimulate people's demands on culture and to transform these demands into cultural productivity. On the other hand, it needs us to dig out the traditional culture resources, develop the existing cultural pattern, update the cultural development form and provide the necessary cultural development form for it. It is needed to find the unique local culture, understand local cultural resources, study special culture, take its essence, and constantly innovate so that the special culture is full of powerful vitality and formed with its own characteristic culture industrial distribution and framework. To continuously improve the culture grade, to create a number of distinctive industry brands, to enhance the national cultural soft power it relies on cultural resources, industrial resources.

\subsection{Dynamic cultivation}

It is needed to develop dynamics of cultural development; what's more it is needed to be cultivated. Culture can cultivate people's inner belief, emotion, reason. This depends on the cultural production. The formation and development of these elements must rely on the cultivation of all kinds of cultural resources, markets, cultural environments, to provide various kinds of development environment for culture innovation. To accelerate the upgrading of the cultural industrial structure, to optimize the cultural market structure, we need to accurately grasp the trends and prospects of cultural development and upgrade the development level, in accord with the economic development, the cultural resource, and the cultural demands in order to promote the sustainable development of cultural industry.

\subsection{Dynamic conversion}

The function of dynamic conversion is to bring the potential power into the real power, to become social activities people engage in to meet their needs the activities of from the driving force of social development as the potential needs to the pursuit of the interests and satisfaction of the needs, finally constitute conversion process. The connotation of dynamic conversion is much abundant, including culture force into productivity or economy, cultural resources into cultural dynamics. The construction of culture needs the conversion of the dynamics of cultural development. We need to promote cultural development, enhance the vitality, attraction of culture and to provide cultural support for strengthening the international competitiveness of 
the economy to through absorbing foreign advanced cultural results and through the integration, and innovation.

\subsection{Dynamic integration}

The integration of the dynamic of cultural development is mainly to adjust or coordinate the conflicts and contradictions of various factors to make it to be a unified whole process. The dynamic itself is not harmonious, since its various and different rules interact contradict mutually, so it must be coordinated around the goal of mutual adaptation to form a balanced, harmonious system, through relevant rules, system and so on. The integration of cultural dynamic goal is to realize the moderate control, appropriate release, with its ultimate aim of implementing the development and prosperity of culture. The ultimate goal of integration is to serve the legal cultural creations, while the real service is not limit but to provide cultural creation platform, give multi-level supports in wealth, resources etc. for people of cultural creation and to inspire people by excellent works .

\subsection{Dynamic feedback}

Dynamic feedback as the whole process of the dynamic of cultural development, it is the last link. Only through the feedback, we can understand: whether the dynamics of cultural development are all-sided; whether the cultivation is appropriate; whether the conservation and the integration are achieved; whether these dynamics promote the benign operation and positive development of cultural development. Dynamic feedback can reflect the formers to work effectively in the whole operation process. in which the corresponding orientation, degrees, methods and so on are adjusted so as to stimulate all dynamics, to make effective integration of various dynamics, and to realize the goal of overall cultural construction.
Dynamic feedback is the last ring of operation. According to the feedback, compared with the original goals of culture development, the policy will be revised and put into practice, then comparing the results of the practice with the planned goal to determine the next step of the policy, through times of comparison to obtain a more optimized program.

\section{CONCLUSION}

The dynamic operation mechanism of cultural development is a systematic engineering. In the process of construction of culture, innovation is required in each system and mechanism in the field of culture. With the development of social productivity, the old system and mechanism will be perfect and optimized, by adapting the needs of economic and social development while the new things and new phenomena requires a new perfect mechanism to develop, so constantly advancing with the times is the indispensable factor for dynamic operation of cultural development. In this way, the policy and resources of the cultural development can be adjusted and enriched constantly, as well as the system and mechanism improved and innovated so that the cultural development can make progress together with the times.

\section{REFERENCES}

[1] Gang. Du, 2012. On the mechanism of cultural creativity and cultural innovation. Heilongjiang Social Sciences 1: 3034.

[2] Xinli. Yang, 2002. The structure, function and operating process of dynamic mechanism of social development. Journal of the Party School of the Central Committee 6: 2833.

[3] Haiyan. Zhang \& Shangfeng Huang. 2007. An Analysis of Structure of Cultural Dynamics in the Social Development. Journal of Hebei North University 23: 24-28. 